\title{
Undergraduate final year nursing students' attitudes toward caring for dying patients: Bahrain's experience
}

Maryam Yaqoob, Husain Nasaif, Hana Kadhom

Royal College of Surgeons in Ireland - Medical University of Bahrain, Kingdom of Bahrain

Received: January 31, 2018

DOI: $10.5430 /$ cns.v6n4p53
Accepted: April 22, 2018

URL: https://doi.org/10.5430/cns.v6n4p53

\begin{abstract}
Background: Nursing students are frequently exposed to dying patients during their clinical placement. Research studies that examined nursing students' attitudes toward caring for dying patients were limited in the Gulf Region, including Bahrain.

Objective: The purpose of this study is to examine the attitudes of fourth-year baccalaureate nursing students regarding caring for dying patients.

Methods: A descriptive cross-sectional design was utilized to recruit a convenience sample of fifty-four nursing students. Frommelt's Attitudes towards Caring of the Dying (FATCOD) five Likert scale was used.

Results: The overall findings revealed that participants had a neutral attitude toward caring for dying patients. The overall attitudes mean score was $3.4 \pm 0.3$. The majority of participants were female $(83 \%, \mathrm{n}=45)$. The difference in the mean score in relation to gender was statistically significant $(p=.049)$. Although the majority of all participants $(80 \%)$ reported having dealt with the terminally ill people in the past, the association between previous experience and reported attitudes was not statistically significant $(p=.31)$.

Conclusions and recommendations: Literature revealed that students who received end of life education where found to have positive attitudes. Therefore, it's crucial to introduce a standalone educational module regarding end of life care early on in the undergraduate curriculum. It is recommended that future studies recruit nursing students from other baccalaureate year levels to reassess the attitudes and level of preparedness following a curriculum reform and implementation of end of life care education. Additionally, a qualitative research method is recommended to explore the lived experience of the nursing students when they are caring for dying patients.
\end{abstract}

Key Words: Attitudes, Nursing students, Caring, Dying patients

\section{INTRODUCTION}

Due to the improvement in socioeconomic status, advancement in both private and public healthcare systems, coupled with the enhanced access to health care services, statistics show that life expectancy has increased in the Kingdom of Bahrain. ${ }^{[1]}$ The life expectancy at birth for Bahrainis of both genders was 75 years between the years 2000-2005; this then increased to 76.5 years between the years 2010-2015. ${ }^{[1]}$
Despite the increase in life expectancy, the mortality rate had also increased due to chronic non-communicable diseases and their progressive complications. Thus, the death rate of patients in hospitals has sharply increased during the past ten years. The total death reported by the two major governmental hospitals was 1,342 patients in 2014. ${ }^{[2]}$

The death of a family member or a beloved one in the hospital setting is a devastating experience that any individual or

\footnotetext{
*Correspondence: Maryam Yaqoob; Email: myaqoob@rcsi.com; Address: School of Nursing \& Midwifery, Royal College of Surgeons in Ireland Medical University of Bahrain, P.O. Box 15503, Adliya, Kingdom of Bahrain.
} 
healthcare provider may encounter. Therefore, nurses need to be conscious of how to deal with the emotional needs of patients at the end of their lives and also that of their family members during this difficult time. ${ }^{[3,4]}$ A study conducted in Kingdom of Bahrain to explore the care practices of nurses at the end of life in intensive care units found that talking about death was avoided by doctors, nurses and relatives. Instead, certain phrases and signals were used to indicate that death is imminent. Moreover, some nurses found it emotionally demanding to be present when the relatives are being informed that the patient is at the end of his/her life. ${ }^{[5]}$

Caring for dying patient is very challenging for both nurses and nursing students. ${ }^{[6,7]}$ Dying patients require high quality of care by nurses and nursing students and they should be well-trained in how to deliver such care. The quality of end of life care is highly dependent on nurses' preparedness, knowledge, experience and attitudes towards caring for dying patients. ${ }^{[3,8-10]}$ One study found that nurses with more work experience ( $>10$ years) have more positive attitudes towards both death and caring for dying patients compared with less experienced nurses. ${ }^{[9]}$ Within the literature several factors have been identified that could positively or negatively affect the attitudes of nursing students toward caring for dying patients. Included in these factors are past experience in dealing with dying patients, religious beliefs, near death experiences, and end of life care education. ${ }^{[11,12]}$

The findings from the studies conducted in the Eastern Mediterranean Region and additional studies from around the globe regarding the attitudes of nursing students toward death and caring for dying patients were inconsistent. For instance, a study conducted in the United Kingdom found that nursing students had positive attitudes, ${ }^{[12]}$ while Jafri and his colleagues from Iran reported negative to neutral attitudes. ${ }^{[11]}$ Several studies found that nursing students feel anxious and unprepared when dealing with dying patients. ${ }^{[4,6,7,11,13]}$ In a qualitative study conducted in Brazil,${ }^{[6]}$ fourteen nursing students reported feelings of anxiety, lack of confidence, and pain when seeing a dying patient who is suffering. These nursing students were additionally afraid of being emotionally hurt when a patient dies and they furthermore felt that they may not be able to deal with the imminence of death. ${ }^{[6]}$ First exposure, not knowing what to do or what to say to dying patients and their relatives are scenarios strongly associated with anxiety among nursing students. ${ }^{[7]}$ Some students described forming a relationship with a terminally ill patient and their family as "complex". Another study reported that first year nursing students were frightened of how they might react when encountering a dying or a recently deceased patient. ${ }^{[4]}$ On the other hand, some nursing students found interacting with dying patients as a positive and enriching ex- perience, yet it could also be distressing as the death of these patients can be difficult. ${ }^{[4]}$ Research studies that assessed the attitudes of nursing students toward caring for dying patients were limited in the Arabian Gulf region, including Bahrain. The purpose of this study was to examine the attitudes regarding caring for dying patients of undergraduate fourth year nursing students during their clinical placement. Additionally, this study explored the association between gender, previous exposure to death and attitudes towards caring for dying patients. Furthermore, this present study aimed to answer the following research questions: (1) What are fourth year nursing students' attitudes towards caring for dying patients? (2) Is there any relationship between gender, and attitudes towards caring for dying patients? (3) Is there any relationship between previous exposure to death and attitudes towards caring for dying patients? Recognizing the factors that might affect nursing students' attitudes toward caring for dying patients will assist educators to adopt measures that enhance students' clinical skills and experience in caring for the dying patients and their families.

\section{Methods}

\subsection{Study setting}

This study was conducted over a six month period from January to May 2011 in a school of nursing and midwifery at a university that provides nursing education at a bachelor and postgraduate level in the Kingdom of Bahrain.

\subsection{Research design \& sample size}

A quantitative, descriptive, cross-sectional design method was utilized to recruit a convenience sample of fifty-four fourth year nursing students.

\subsection{Study instrument}

Frommelt's Attitudes towards Caring of the Dying (FATCOD-form A) questionnaire with a Likert scale was used to measure nurses attitudes during their clinical placement toward caring for dying patients. Permission to use the questionnaire was obtained from the developer. FATCOD is a self-administered questionnaire developed by Katherine Murry Frommelt in 1988 in the United States. ${ }^{[14]}$ It was widely used in the literature during the past ten years. ${ }^{[9,11-13,15]}$ The validity of the questionnaire was assessed by the developer using the scale content validity index (SCVI) and an interrater agreement. The SCVI was found to be 1.00 and the interrater agreement was 0.98 . The reliability of the FATCOD scale was 0.90 using the test - retest approach. ${ }^{[14]}$ The FATCOD was initially developed in English language. Furthermore, the reliability of the questionnaire was measured by other researchers after it had been translated to other languages. ${ }^{[9,16,17]}$ For example, the Chronbach 
Alpha was 0.90 after being translated into Arabic language. ${ }^{[9]}$

The questionnaire consisted of fifteen positively and fifteen negatively worded statements using a five point Likert scale to indicate participants' responses for each statement. The response to each statement was rated from 1 (Strongly Disagree) to 5 (Strongly Agree). A pilot study which consisted of eight nursing students was conducted to determine the time required to complete the questionnaire and ensure its clarity, considering English was not the first language of the study participants. The outcome of the pilot study revealed that no modification needed to be made to the questionnaire based on the feedback received from the participants. Those individuals who participated in the pilot study were also included in the actual study. In addition to the Likert questions, the first part of the questionnaire captured demographic data such as age, gender, and highest educational degree held, previous end of life care education and previous experience in dealing with terminally ill people. The participants were asked to complete the FATCOD questionnaire in one of the classrooms in the university after finishing their teaching schedule.

\subsection{Ethical considerations}

Ethical approval was obtained from the ethics committee of the university where the study took place. Prior to data collection, the purpose of the study was explained to the participants and an informed consent was obtained. The confidentiality and anonymity were assured. The participants were informed that they had the right to withdraw from the study at any time without any penalty.

\subsection{Data analysis}

Statistical Package for the Social Science (SPSS) version 18 software was used for data analysis. Descriptive statistics including frequency, percentage and standard deviation were used to describe the demographic data and the items of FATCOD scale. Mann-Whitney tests were used to detect the difference in attitudes mean score in relation to age, gender and previous exposure in dealing with dying patients. The scores for all negatively worded statements were reversed before analyzing the data.

\section{Results}

\subsection{Sample characteristics}

Fifty-four students completed the questionnaire. Table 1 illustrates the demographic characteristics of the study participants and previous experience in dealing with terminally ill people.
Table 1. Sample demographic characteristics and previous experience in dealing with terminally ill people $(n=54)$

\begin{tabular}{llll}
\hline Variable Name & Category & $\mathbf{n}$ & $\mathbf{\%}$ \\
\hline \multirow{3}{*}{ Age } & 18-22 years & 49 & 90.7 \\
& $>$ 22 years & 5 & 9.3 \\
& Total & 54 & 100 \\
Gender & Male & 9 & 16.7 \\
& Female & 45 & 83.3 \\
Experience in dealing with & Total & 54 & 100 \\
terminally ill people & Yes & 43 & 79.7 \\
& No & 11 & 20.3 \\
& Total & 54 & 100 \\
\hline
\end{tabular}

The majority of participants were female $(83 \%, n=45)$ while males represented $17 \%$ of the study sample $(n=9)$. The majority of the study participants $(90.7 \%)$ were in the age group of $18-22$ and $9.3 \%$ were above 22 years of age. Of all participants, $84 \%$ reported having previous experience in dealing with terminally ill people.

\subsection{Attitudes toward caring for dying patients}

According to FATCOD scale, scores 3.5 and above are indicative of positive attitudes while scores below 2.5 are indicative of negative attitudes. The scores that fall between 2.6 to 3.4 are considered neutral. Table 2 shows the responses to FATCOD statements.

The study revealed that the overall attitudes mean score was $3.4 \pm 0.3$. The question with the highest mean score was $4.3 \pm 0.9$ for number 21 which stated, "It is beneficial for the dying person to verbalize his/her feelings." The lowest mean score was $2.2 \pm 1.1$ for statement 19 which said, "The dying person should not be allowed to make decisions about his/her physical care." The mean scores of 4 and above were obtained for statements 4,12,16,18, 20 and 22. On the other hand, the mean score was below 2.6 for statements 17 and 19.

\subsection{The relationship between attitudes and sample char- acteristics}

The difference in the attitudes mean score in relation to age, gender and previous experience in dealing with dying patients was measured by the Mann-Whitney test. Table 3 shows the relationship between demographic variables and attitudes.

The findings of this study revealed that there were no significant differences in the mean score in relation to age $(p=.73)$ and previous experience in dealing with dying patients $(p=.312)$. The difference in the mean score in relation to gender was statistically significant $(p=.049)$. 
Table 2. Responses to FATCOD scale statements $(\mathrm{n}=54)$

\begin{tabular}{|c|c|c|c|}
\hline \multicolumn{2}{|c|}{ Scale Statements } & \multirow{2}{*}{$\begin{array}{l}\text { Mean } \\
3.9\end{array}$} & \multirow{2}{*}{$\frac{S D}{1.1}$} \\
\hline 1. & Giving nursing care to the dying person is a worthwhile learning experience. & & \\
\hline 2. & Death is not the worst thing that can happen to a person. & 3.4 & 1.4 \\
\hline 3. & I would be uncomfortable talking about impending death with the dying person. & 3.6 & 1.0 \\
\hline 4. & Nursing care for the patient's family should continue throughout the period of grief and bereavement. & 4.0 & 1.2 \\
\hline 6. & The nurse should not be the one to talk about death with the dying person. & 3.2 & 1.4 \\
\hline 7. & The length of time required to give nursing care to a dying person would frustrate me. & 2.9 & 1.1 \\
\hline 8. & I would be upset when the dying person I was caring for gave up hope of getting better. & 3.7 & 1.1 \\
\hline 9. & It is difficult to form a close relationship with the family of the dying person. & 3.3 & 1.2 \\
\hline 10. & There are times when death is welcomed by the dying person. & 3.7 & 1.0 \\
\hline 11. & When a patient asks, "Nurse, am I dying?" I think it is best to change the subject to something cheerful. & 3.1 & 1.2 \\
\hline 12. & The family should be involved in the physical care of the dying person. & 4.1 & 1.0 \\
\hline 13. & I would hope the person I'm caring for dies when I am not present. & 3.3 & 1.1 \\
\hline 14. & I am afraid to become friends with a dying person. & 2.9 & 1.3 \\
\hline 15. & I would feel like running away when the person actually died. & 2.9 & 1.2 \\
\hline 16. & Families need emotional support to accept the behavior changes of the dying person. & 4.2 & 1.0 \\
\hline 17. & As a patient nears death, the nurse should withdraw from his/her involvement with the patient. & 2.4 & 1.2 \\
\hline 18. & Families should be concerned about helping their dying member make the best of his/her remaining life. & 4.0 & 0.9 \\
\hline 19. & The dying person should not be allowed to make decisions about his/her physical care. & 2.2 & 1.1 \\
\hline 20. & Families should maintain as normal an environment as possible for their dying member. & 4.0 & 0.8 \\
\hline 22. & Nursing Care should extend to the family of the dying person. & 4.1 & 0.9 \\
\hline 23. & Nurses should permit dying persons to have flexible visiting schedules. & 3.8 & 1.0 \\
\hline 24. & The dying person and his/her family should be the in-charge decision makers. & 3.8 & 1.1 \\
\hline 25. & Addiction to pain relieving medication should not be a concern when dealing with a dying person. & 3.4 & 1.4 \\
\hline 26. & I would be uncomfortable if I entered the room of a terminally ill person and found him/her crying. & 3.5 & 1.0 \\
\hline 27. & Dying persons should be given honest answers about their condition. & 3.9 & 1.1 \\
\hline 28. & Educating families about death and dying is not a nursing responsibility. & 2.6 & 1.3 \\
\hline 29. & Family members who stay close to a dying person often interfere with the professionals' job with the patient. & 3.5 & 1.0 \\
\hline 30 . & It is possible for nurses to help patients prepare for death. & 3.8 & 1.0 \\
\hline The & erall mean score & 3.4 & 0.3 \\
\hline
\end{tabular}

Table 3. The association between the demographic characteristics and attitudes toward caring for dying patients

\begin{tabular}{|c|c|c|c|c|c|}
\hline Variable Name & Category & Mean & $S D$ & Test & $p$ value \\
\hline \multirow{2}{*}{ Age } & $18-22$ years & 3.4 & 0.3 & \multirow{2}{*}{ Mann-Whitney } & \multirow{2}{*}{.731} \\
\hline & $>22$ years & 3.4 & 0.5 & & \\
\hline \multirow{2}{*}{ Gender } & Male & 3.3 & 0.3 & \multirow{2}{*}{ Mann-Whitney } & \multirow{2}{*}{$.049^{*}$} \\
\hline & Female & 3.5 & 0.3 & & \\
\hline \multirow{2}{*}{ Experience in dealing with terminally ill people } & Yes & 3.5 & 0.3 & \multirow{2}{*}{ Mann-Whitney } & \multirow{2}{*}{.312} \\
\hline & No & 3.3 & 0.3 & & \\
\hline
\end{tabular}

Note. ${ }^{*} p \leq .05$ sig two tailed 


\section{Discussion}

This study recruited only fourth year nursing students because they had more clinical exposure compared to the second and third year students. Several previous studies also recruited students in their final year, ${ }^{[11,15]}$ whereas other studies compared the attitudes toward dying patients among students from different years of study within their nursing program. ${ }^{[12,18]}$ The overall findings from this study revealed that participants had neutral attitudes toward caring for dying patients. This finding was consistent with another study conducted in Iran which had a mean score of 3.5 on FATCOD scale before educational intervention. ${ }^{[11]}$ In general, findings from various previous studies were inconsistent regarding nursing students' attitudes toward caring for dying patients. Some studies reported positive, ${ }^{[12,15,19]}$ whereas others reported negative attitudes. ${ }^{[11,13]}$

Although the overall attitudes were neutral in this present study, participants had positive attitudes toward issues concerning involving of the family members in the decision making and caring for dying patients. The involvement of family members in the care of dying patients sometimes depends on their relationship with the healthcare providers. Nursing students believe that it is difficult to form a close relationship with the family of the dying patient. Forming such relationship is painful as it involves suffering and grieving. ${ }^{[20]}$

The findings from this present study also indicated that there was an association between gender and attitudes towards caring for dying patients. The difference was statistically significance $(p=.049)$. This finding was inconsistent with other studies. ${ }^{[12,21]}$ According to previous studies, the nature and length of previous experience in dealing with terminally ill people could influence the attitudes towards caring for dying patients. ${ }^{[9,12,13]}$ Although the majority of students $(n=43)$ in our present study reported dealing with a terminally ill people in the past (79.7\%), the association between previous experience and attitudes toward caring for dying patients was not statistically significant $(p=.31)$. One possible reason for this finding is the lack of in-depth end of life education in the undergraduate nursing curriculum. Previous studies revealed that end of life education was associated with positive attitudes towards caring for dying patients. ${ }^{[10,11,15]}$ Nursing students who received end of life education were found to have positive attitudes toward caring for dying pa- tients. ${ }^{[13]}$ In a study conducted by Bailey \& Hewison, ${ }^{[5]}$ the FATCOD scores were greater amongst students who completed an educational workshop on death compared with those who had not completed any $(p=.01)$. In the School of Nursing where this study was conducted, the undergraduate nursing curriculum had a limited emphasis on end of life education. Therefore, it appears to be crucial to introduce a standalone educational module regarding end of life care early on in the undergraduate nursing program curriculum. It should be noted that an Oncology Centre in the university teaching hospital in which our present students receive their clinical training has lately been opened. Therefore, in relation to this, it is critical that nursing students are well prepared to handle end of life issues.

Although this study was conducted six years ago, the findings from the recent studies that examined the same topic revealed that nursing students still had negative attitudes and felt unprepared when caring for dying patients. ${ }^{[11,12]}$ The sample size in our study was relatively low and this limited the generalizations of the study findings. Another limitation in this study was that it recruited only final year nursing students, thus there is a need to include nursing students from other year levels because of their early clinical exposure and involve the other school of nursing in Bahrain. The attitudes and preparedness of nursing students to provide end of life care should be reassessed again after curriculum reform has occurred and implementation of end of life care education is put in place. Most of the studies examining the attitudes of nursing students toward caring for dying patients have used quantitative research methods and this present study is not an exception. A mixed method approach is recommended to explore the lived experiences when caring for dying patients and their family members.

\section{ACKNOWLEDGeMENTS}

This study was done and submitted in part fulfillment of the degree of Master in Science in Nursing, Faculty of Nursing and Midwifery, Royal College of Surgeons in Ireland - Medical University of Bahrain. We would like to extend our appreciation to the Palm Association for sponsoring the primary investigator of this study to continuing the master education.

\section{CONFLICTS OF INTEREST DISClOSURE}

The authors declare they have no conflicts of interest. 


\section{REFERENCES}

[1] Bahrain Health statistics. Ministry of Health, Kingdom of Bahrain. 2015.

[2] Bahrain Health statistics. Ministry of Health, Kingdom of Bahrain. 2014.

[3] Razban F, Iranmanesh S, Rafiei H. Nurses' attitudes toward palliative care in southeast Iran. International Journal of Palliative Nursing. 2013 Aug; 19(8): 403-10. PMid: 23970297. https: //doi.org/10.12968/ijpn.2013.19.8.403

[4] Ek K, Westin L, Prahl C, et al. Death and caring for dying patients: exploring first-year nursing students' descriptive experiences. International Journal of Palliative Nursing. 2014 October; 20(10): 509-15 PMid: 25350217. http://data.worldbank.org/indicator/S H. XPD . PCAP

[5] O'Neill CS, Yaqoob M, Faraj S, et al. Nurses' care practices at the end of life in intensive care units in Bahrain. Nursing Ethics. 2017; 24(8): 950-61. PMid: 26908043. https ://doi .org/10.1177/09 69733016629771

[6] Sadala MLA, da Silva FM. Taking care of terminal patients: nursing students' perspective. Revista da Escola de Enfermagem da USP. 2009; 43(2): 287-94. https ://doi .org/10.1590/S0080-62342 009000200005

[7] Youssef HAM. Nursing students' perception of dying and their contextualizing end of life and palliative care in nursing curriculum at Taif University. European Journal of Academic Essays. 2016[cited 2017 October 9]; 3(5): 193-99. Available from: http://euroessays.org/wp-content/uploads/2016/ 08/EJAE-1608-527.pdf

[8] Choi M, Lee J, Kim S, et al. Nurses' knowledge about end-of-life care: where are we? The Journal of Continuing Education in Nursing 2012; 43(8): 379-84. PMid: 22715872. https ://doi.org/10.3 928/00220124-20120615-35

[9] Abu Hasheesh MO, AboZeid SA, El-Said SG, et al. Nurses' characteristics and their attitudes toward death and caring for dying patients in a public hospital in Jordan. Health Science Journal. 2013; 7(4): 384-394. Available from: http://www.hsj.gr/medicine/nurses-characteristi cs-and-their-attitudes-toward-death-and-caring-for -dying-patients-in-a-public-hospital-in-jordan.pdf

[10] Iranmanesh S, Razban F, Tirgari B, et al. Nurses' knowledge about palliative care in Southeast Iran. Palliative and Supportive Care. 2014 June; 12(3): 203-10. PMid: 23905678. https ://doi .org/10.101 $7 /$ S1478951512001058

[11] Jafari M, Rafiei H, Nassehi A. Caring for dying patients: Attitude of nursing students and effects of education. Indian Journal of Palliative Care. 2015; 21(2): 192-97. PMid: 26009673. https://doi.org/10.4103/0973-1075.156497
[12] Grubb C, Arthur A. Student nurses' experience of and attitudes towards care of the dying: A cross-sectional study. Palliative Medicine. 2016; 30(1): 83-88. PMid: 26577928. https ://doi .org/10.117 $7 / 0269216315616762$

[13] Hagelin CL, Melin-Johansson C, Henoch I, et al. Factors influencing attitude toward care of dying patients in first-year nursing students. International Journal of Palliative Nursing. 2016; 22(1): 28-36. PMid: 26804954. https://doi.org/10.12968/ijpn.2016.22.1.28

[14] Formmmelt KHM. The effects of death education on nurses' attitude toward caring for dying terminally ill persons and their families. The American Journal of Hospice and Palliative Care. 1991; 8(3): 37-43. PMid: 1742142. https://doi.org/10.1177/10499091910080 0509

[15] Bailey C, Hewison A. The impact of a 'critical moments' workshop on undergraduate nursing students' attitudes to caring for patients at the end of life: an evaluation. Journal of Clinical Nursing. 2014; 23 : 3555-3563. PMid: 24942552. https://doi.org/10.1111/jocn .12642

[16] Henoch I, Browall M, Melin-Johansson C, et al. The Swedish version of the Frommelt attitude toward care of the dying scale: aspects of validity and factors influencing nurses' and nursing students' attitudes. Cancer Nursing. 2014; 37(1): E1-11. https ://doi.org/10.109 $7 /$ NCC. Ob013e318279106b

[17] Edo-Gual M, Tomás-Sábado J, Gómez-Benito J, et al. Spanish adaptation of the Frommelt attitude toward care of the dying Scale (FATCOD-S) in Nursing Undergraduates. Omega (Westport). 2017. https://doi .org/10.1177/0030222816688294

[18] Strang S, Bergh I, Ek K, et al. Swedish nursing students' reasoning about emotionally demanding issues in caring for dying patients. International Journal of Palliative Nursing. 2014; 20(4): 194-200. PMid: 24763328. https ://doi.org/10.12968/ijpn.2014.20. 4.194

[19] Bassah N, Cox K, Seymour J. A qualitative evaluation of the impact of a palliative care course on preregistration nursing students' practice in Cameroon. BMC Palliative Care. 2016; 15(37): 1-13. https://doi.org/10.1186/s12904-016-0106-7

[20] Cooper J, Barnett M. Aspects of caring for dying patients which cause anxiety to first year student nurses. International Journal of Palliative Nursing. 2005; 11(8): 423-30. PMid: 16215518. https : //doi.org/10.12968/ijpn.2005.11.8.19611

[21] Frommelt KH. Attitudes toward care of the terminally ill: an educational intervention. American Journal of Hospice and Palliative Care. 2003; 20(1): 13-22. PMid: 12568433. https://doi.org/10.117 $7 / 104990910302000108$

[22] Henoch I, Melin-Johansson C, Bergh I, et al. Undergraduate nursing students' attitudes and preparedness toward caring for dying persons - A longitudinal study. Nurse Education in Practice. 2017; 26: 1220. PMid: 28648955. https ://doi.org/10.1016/j.nepr. 201 7.06 .007 